\title{
An industry analysis of pharmaceutical production in South Africa
}

\author{
C. te W. Naudé \\ Wits Business School, PO Box 98, Wits 2050, \\ Republic of South Africa \\ J.M. Luiz* \\ Graduate School of Business, University of Cape Town, \\ Private Bag X3, Rondebosch 7701, Republic of South Africa \\ john.luiz@gsb.uct.ac.za
}

\begin{abstract}
The purpose of this research is to investigate the shifting structure of pharmaceutical production in South Africa and examine the global and local factors that have contributed to this change. Generally, these factors have resulted in a decline in the number of pharmaceutical manufacturers in South Africa and in particular manufacturing operations owned by multinational companies. Simultaneously the global demand for generic medicines has increased due to their ability to improve access to affordable medicines. As a result, the supply of medicines in South Africa is being increasingly met by imported generic medicines and to a lesser extent locally manufactured generic medicines. These changes, together with a turbulent and sometimes uncertain regulatory environment, have led to interesting dynamics and changes within the structure of the pharmaceutical manufacturing industry in South Africa.
\end{abstract}

*To whom all correspondence should be addressed.

\section{Introduction}

In South Africa's years of isolation from the international market prior to 1994, the local pharmaceutical industry was able to develop in terms of skills and infrastructure. Within this period, however, the provision of healthcare was not uniformly and equitably distributed amongst all members of the population (FRIDGE, 1999; Maloney \& Segal, 2007). After the first democratic elections in 1994 the new government began to address this disparity by implementing policies and regulations to increase the affordability and accessibility of medicines for all sectors of the population. In essence this has been successful, as expenditure on medicines in South Africa has decreased (CMS, 2007; McIntyre \& Thiede, 2007; Taylor, 2007). But the country has also seen a decline in the number of pharmaceutical production facilities in South Africa, as highlighted by large-scale industry reports (FRIDGE, 1999; Maloney \& Segal, 2007).

The purpose of this research is to explore the recent changing structure of production within the South African pharmaceutical industry. The research focuses on the recent trends in the global pharmaceutical industry, followed by an analysis of local production in response to a changing business environment.

\section{Literature review}

There has been a restructuring in the global pharmaceutical industry since the early 1990s (Cockburn, 2004; Heracleous \& Murray, 2001; Scherer, 1993; Yeoh \& Roth, 1999). This restructuring within pharmaceutical production and manufacturing has led towards the development of "centres of excellence," where companies focus their production and manufacturing activities in a select number of countries. These countries are typically selected in terms of having the right combination of skills, a beneficial geographic location in the world market and the provision of government investment incentives to companies. This, coupled with the global trend towards mergers and acquisitions (M\&A), has led to these companies becoming more cost effective and profitable.

From the early 1970s, countries in the developing world, especially India and China, had focused mainly on generic drug manufacturing. These countries are now starting to form partnerships with R\&D pharmaceutical companies in the developed world (Maloney \& Segal, 2007). These partnerships are formed across the pharmaceutical value chain, for example $\mathrm{R} \& \mathrm{D}$, drug production and clinical trials. This development has allowed companies from the developed world to cut costs as the developing countries can provide the companies with

- $\quad$ skilled labour;

- $\quad$ low-cost research facilities;

- low-cost drug development sites, especially in terms of clinical trials;

- low-cost licensed or contract manufacturing; 
- low-cost distribution of drugs; and/or

- $\quad$ low-cost sales and marketing (Maloney and Segal, 2007).

The South African pharmaceutical manufacturing industry in the late 1990s was well developed and, while operating within a relatively protected environment, it had become the most developed and largest pharmaceutical industry in Africa (FRIDGE, 1999). Despite this, however, globalisation and the restructuring of the pharmaceutical industry and in particular the increase in production of generic drugs in India had by the late 1990s resulted in a decline in employment within the local pharmaceutical manufacturing industry, which was about half of what it had been in the 1980s (FRIDGE, 1999).

The industry's global restructuring process towards "centres of excellence" has not benefited the South African pharmaceutical industry. This is evident in the steady decline in the number of multinational pharmaceutical manufacturing facilities operating in South Africa (FRIDGE, 1999; Maloney \& Segal, 2007). In the five years prior to the FRIDGE Study (1999) conducted in 1999, over 30 companies closed their manufacturing facilities. The main reasons for these closures included downsizing of operations, rationalisation, $M \& A$, the increased tendency to import drugs and reasons relating to cost, which, in turn, were related to increased registration times.

Maloney and Segal (2007) found that of the 16 multinational pharmaceutical companies operating in South Africa in 2007 only ten still have manufacturing facilities, while the remaining six have contracted local companies to manufacture and pack their products. They further found that 35 pharmaceutical plants have closed down in South Africa since 1994, the majority being multinational R\&D companies. This has led to a decrease in the number of people employed in the local pharmaceutical manufacturing industry. In 2000, 16,000 people were employed by this industry (this number was estimated at 18,000 in 1999 (FRIDGE, 1999) and 18,000 in 2001 (Beare, 2001)) Employment in this industry had been reduced to 11,000 employees by 2007 as a direct result of the closure of manufacturing facilities (Maloney \& Segal, 2007).

The FRIDGE Study (FRIDGE, 1999) found that owing to the opening of the South African economy the total market for wholly imported drugs was 30 per cent compared to 15 per cent ten years prior to the study. Maloney and Segal (2007) also found that in 1998 the ratio of imported medicines ready for sale to locally produced medicines ready for sale was 8:1. By 2006 this ratio had increased to $17: 1$. These ratios do not take into account the imported APIs and other inputs required for the local production of medicines. There has therefore been an increased use of imported medicines relative to locally produced medicines.

There are various obstacles that the local pharmaceutical manufacturing industry has to overcome. The major ones are outlined below.

\section{Manufacturing capacity}

The FRIDGE Study (1999) found that in the late 1990s there was excess pharmaceutical manufacturing capacity in South Africa. At this stage it would have been possible for a new manufacturer to become established by merely contracting the production to existing manufacturers with spare capacity. The problem, however, was that the capital equipment and facilities in most cases were old and the technology was in some cases outdated. Machinery would have needed replacement to prevent the constant need for maintenance and therefore additional capital expenditure was required to attain a competitive level of output. These manufacturing plants were equipped with technology that was outdated and produced volumes that were too low to supply the international market. The running costs of these plants were therefore high relative to the volumes that they were producing at the time. In comparison with Asian manufacturing plants, the unit costs of the local factories were five times higher. The lack of sufficient local capacity and economies of scale therefore led to a loss of competitiveness in terms of prices of locally produced medicines when compared to imports.

\section{South African drug policy}

Since 1994 the government has introduced significant shifts in government policies in an attempt to address inequalities in the pharmaceutical and healthcare sectors. These shifts have had some negative side effects, particularly within the pharmaceutical industry as it has affected the profitability of production (discussed below). In September 1994 the Minister of Health appointed a Drug Policy Committee to establish the NDP with the aim of developing the following:

- A pricing plan for drugs used in the public and private sectors of South Africa.

- A plan for testing drugs and an evaluation of the effectiveness of drugs, based on epidemiological approaches in the South African context.

- An essential drugs list and treatment guidelines for the health personnel for usage in the public sector.

- $\quad$ Strategies for the increased usage of generic drugs.

- A procurement and distribution plan for drugs in South Africa which effectively increases drug access in the rural areas.

- A rationalisation of pharmaceutical services (DOH, 1996).

\section{The pricing of pharmaceuticals in South Africa}

Since 1997 The Medicines and Related Substances Control Amendment Act 90 of 1997 and the regulations relating to a transparent pricing system for medicines and scheduled substances have been the government's main legislative drives in making healthcare more affordable in South Africa (Taylor, 2007). The government's Medicines Pricing Committee has successfully implemented the Single Exit 
Price (SEP). The pricing policies of the government have had the main purpose of regulating and lowering drug prices in order to make medicines more affordable. Maloney and Segal (2007) comment that most stakeholders believe that the policies lack transparency and economic feasibility, even though they accept the government's goals of improving the access to and affordability of medicines.

\section{The public sector procurement of medicines}

The tender price preference system is a useful way for local manufacturers to secure demand for certain products that they supply to the public sector. This demand helps to utilise spare capacity and spread the overheads of a manufacturing facility over a greater number of units for the duration of the tender. Without a secure demand, the manufacturer would more than likely have to base its forecast of demand on more fickle market trends and other expenses, for example marketing costs, would also increase as a demand would have to be created in the market. The government's procurement system of medicines for the public sector also raises concerns with regard to the effect that it has on the local pharmaceutical manufacturing industry. The procurement takes into consideration a ten-point system. Of these ten points four points are awarded for local content, four points for Black Economic Empowerment (BEE) compliance and the remaining two points for purchasing from small and medium enterprises (SMEs). Companies can then tender for providing high volumes of drugs to the public sector for three years in the case of ARVs and two years for any other drugs. Maloney and Segal (2007) claim that importers of drugs can manipulate the government's ten-point system for preferential procurement. These importers simply have to open up a small office with a small BEE compliant staff to attain a higher score. In contrast local manufacturing companies with a large staff complement would find it harder to be BEE compliant.

\section{Skills shortages and pharmaceuticals as a knowledge sector}

The pharmaceutical manufacturing industry requires a unique and specific set of skills, especially when one considers the range of skills required in the production, registration and marketing of medicines. Maloney and Segal (2007) assert that the government's focus on primary healthcare has resulted in a diminished focus on tertiary healthcare as is evident in the decreased government funding of tertiary education in universities.

\section{Intellectual property rights (IPRs)}

Patented medicine producers seek to protect their intellectual property in order to set higher prices which enable the manufacturer to recover $R \& D$ costs. In an attempt to lower the costs of medicines in South Africa so as to improve the public's access to medicines, the Medicines and Related Substances Control and Amendment Act of 1997 has made provision for compulsory licensing, parallel importing and mandatory generic substitution. In mandatory generic substitution, South African pharmacists are required to dispense cheaper generic substitutes unless the doctor or patient insists on using the patented version of the same drug.

Maloney and Segal (2007) conclude that:

- the sector is essential in terms of providing healthcare and is therefore of strategic significance in order to secure the supply of medicines in South Africa, which has a rising incidence of infectious diseases; and

- $\quad$ the sector does show growth potential to supply drugs for infectious diseases found in sub-Saharan Africa in partnership with other countries.

South Africa needs to decide whether its drug market should be restricted to a local market or broadened out to an export market. The focus of the market then has to be decided and this could either be a focus on developing the entire pharmaceutical value chain or creating a competitive niche in strategic products and activities (Maloney and Segal, 2007).

These two dimensions are illustrated in Figure 1. The dimensions provide four main strategic areas that become possible when the two dimensions are combined. These main strategic areas are the North West (NW), the North East (NE), the South West (SW) and South East (SE) quadrant strategies. Up until recently, South Africa followed the SW quadrant strategy, where it attempted to substitute local production and activities across the value chain with imports. This strategy is uncompetitive and inefficient when confronted with global competition and produces very little for an export market. Maloney and Segal (2007) suggest that South Africa has the ability to develop sustainable competitive advantages in areas where it has demonstrated potential. In doing so, it can first meet the demand of the local and regional markets before expanding to export markets as its competitiveness increases in global terms. Interestingly since this 2007 study we have seen positive movements in this direction and there is further potential for this development. 


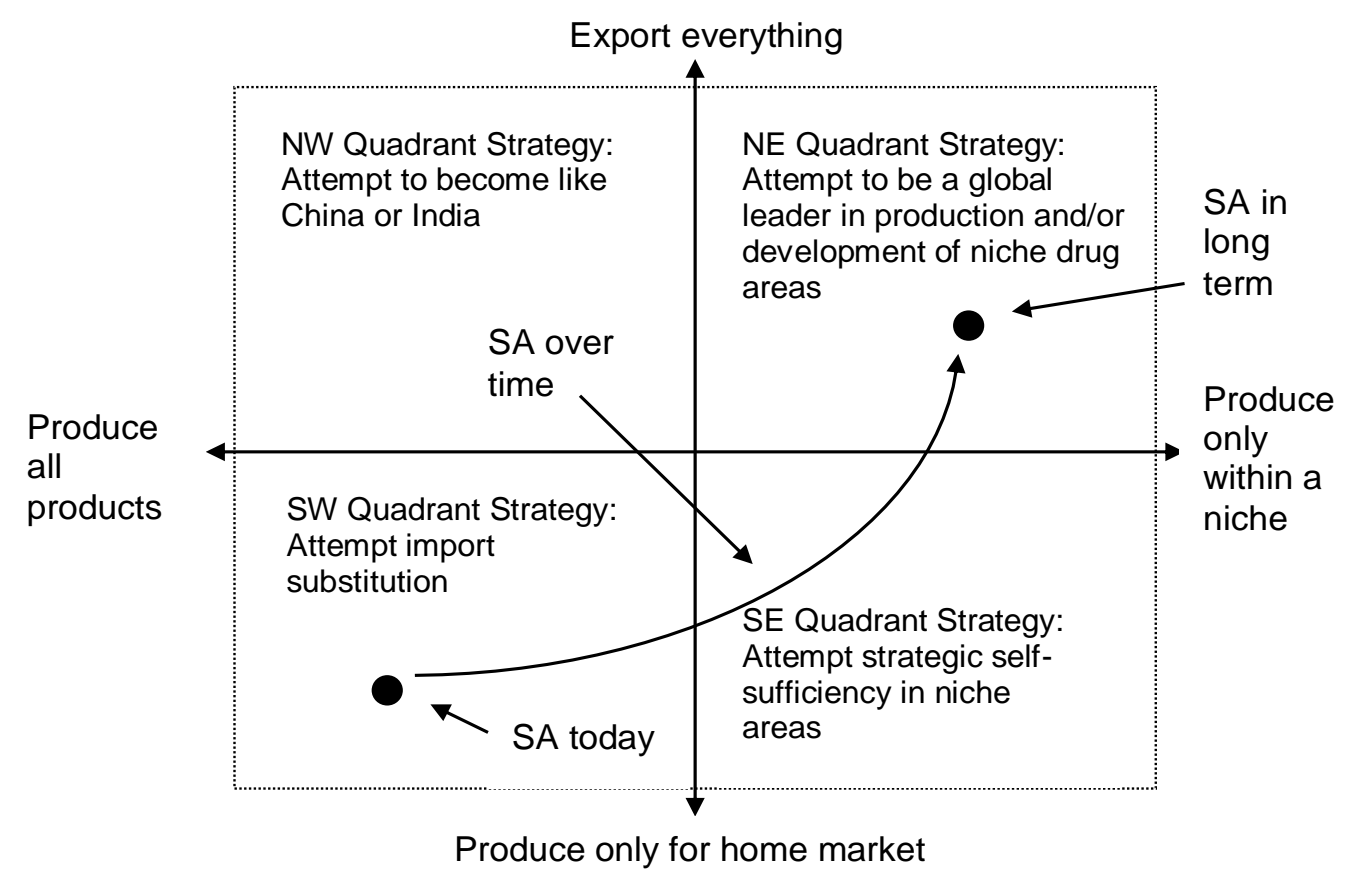

Figure 1: Proposed way forward for pharmaceuticals in South Africa Source: Maloney and Segal, 2007

The economic liberalization of the 1990s resulted in the collapse of pharmaceutical industries in some locations and the rise of new competitors in others. Chittoor et al. (2009) discuss the emergence of third-world copycat producers which saw the Indian pharmaceutical industry come to the fore. Using longitudinal data on 206 Indian pharmaceutical firms from 1995-2004 they find that firms' access to international technological and financial resources have enabled product market internationalization. They maintain that the exogenous shocks, in the form of comprehensive institutional reforms that changed the global rules of the game affected the players and changed their dynamic capabilities. They illustrate that Indian firms took the international offensive strategy by engaging in an iterative process of resource and product market reconfiguration. In contrast to South Africa's reaction to these global developments whereby it tried to protect the local industry through barriers, the Indians enabled better export performance by facilitating the acquisition of international resources (including technology) to complement indigenous advantages. Likewise Athreye, Kale and Ramani (2009) shows that radical regulatory changes such as the Indian Patent Act of 1970, the New Industrial Policy of 1991 and the signing of TRIPS in 1995 served to open up economic opportunities for those companies and countries that developed dynamic firm capabilities. While much of the discussion below on South Africa will point to the passive response of South African pharmaceutical companies to these international developments, the global evidence is that those that have thrived seized the opportunities presented by these flattening economic forces. Athreye et al. (2009) argue that dynamic capabilities evolve over time due to endogenous market changes and exogenous shocks. These disruptions provide opportunity for renewal and the redeployment of existing capabilities. They find that Indian firms exploited these new opportunities by i) entering into the generic markets of developed countries, ii) collaborating with Western multinationals on different segments of the sequential process of new drug commercialization, and iii) acquiring skills for new drug discovery and commercialization.

\section{Research methodology}

This research was exploratory in nature and a qualitative approach was used to investigate the responses to the research questions (see Appendix A for research instrument), which were asked in interviews with stakeholders within the pharmaceutical industry. The targeted population includes all the stakeholders within the South African pharmaceutical industry that have a direct connection with pharmaceutical production or have the ability to influence the nature or structure of pharmaceutical production in South Africa. A sample of 13 individuals was selected to take part in the interviews all of which were in senior management positions (see Appendix B for list of respondents). Interviews were conducted face-to-face to allow for probing and further discussion of the research questions. To reduce the biased nature of the sample individuals from different areas of the industry were selected. Three individuals from MNCs involved in local manufacturing were interviewed; one of these individuals represented a large MNC specialising in generic medicines. Three individuals from each of the three largest local manufacturers were interviewed as well as two individuals from smaller local manufacturers, one of which is involved exclusively in contract manufacturing. One respondent was selected from the $\mathrm{DOH}$ and more specifically from the MCC, and another from the DTI in order to gain the government's perspective on the research topic. Two individuals were selected from industry organisations and, lastly, one individual was selected from a professional 
organisation that represents pharmacists in the pharmaceutical industry. The selected individuals all had either direct involvement or intimate knowledge of the local pharmaceutical production industry.

\section{Presentation and discussion of results}

The global pharmaceutical industry's impact on the changing structure of South African pharmaceutical production

All of the respondents indicated that the two largest global factors that influenced local pharmaceutical production have been the consolidation of global manufacturing activities of MNCs and the increased global usage of generic medicines.

\section{Consolidation of global pharmaceutical production}

All the respondents agreed that the single biggest global factor that has influenced pharmaceutical production by both South African companies and MNCs in South Africa has been the events that have taken place within global pharmaceutical manufacturing in recent decades. In the last 15 to 20 years global pharmaceutical manufacturing by MNCs has undergone a transition, whereby MNCs have consolidated their manufacturing facilities globally to create centres of excellence. These centres are typically large consolidated manufacturing facilities that often produce specific drugs or drug categories for geographic regions, particular markets and in some cases for the entire global market of an MNC. Previous to this period in the late 1980s and early 1990s MNCs often had many manufacturing facilities globally in countries where they had marketing, sales and distribution activities.

The main drive towards establishing these centres of excellence has been to achieve two objectives simultaneously. First, economies of scale can be achieved when large volumes of a limited variety of drugs are produced in one facility. All companies and industry organisations interviewed were in agreement that this drive to lower costs and improve production efficiencies has also been motivated by the MNCs' need to remain viable and sustainable in markets. Secondly, by producing the total supply of a drug for the global market in one facility a manufacturer would also be able to maintain and assure uniform high quality standards of produced drugs. A respondent from a large multinational generic company commented that the emphasis on high drug quality standards has become both a requirement and an expectation globally, regardless of whether the drug is a new innovative drug or a generic drug.

Five of the respondents argued that merger and acquisition (M\&A) activity amongst MNCs further resulted in the establishment of centres of excellence. The main reason for the M\&A activity in this industry has been to gain synergies in $R \& D$ capabilities that result in the delivery of new innovative drugs that can be protected by a patent. Typically with this trend the manufacturing functions of the merged companies would also be consolidated and merged in order to achieve manufacturing synergies and uniform quality controls over the production of a larger variety of drugs.
Half of the people interviewed, and in particular those affiliated to large MNCs, agreed that the centres of excellence are mostly established in countries or regions that fulfil certain criteria. These criteria most often include cost advantages such as tax incentives and other incentives provided by the governments of these countries in order to attract foreign direct investment (FDI). In addition to this, these countries often have a large skills base as a result of high education standards coupled with a relatively low cost of skilled and semi-skilled labour. Countries like Puerto Rico, Brazil, Singapore, China and most notably India were given as examples of nations that provided the MNCs with attractive incentives for the establishment of these centres of excellence. A respondent from a large local generic company commented that the MNCs assess the political climate, infrastructure and economic stability of these countries prior to investing in regional manufacturing facilities in order to minimise the risks of such large investments.

Individuals from both industry organisations and a government department that were interviewed emphasised that at the time of these developments the South African government had perhaps not provided global MNCs with sufficient incentives to invest in the expansion of their existing operations or in the establishment of new large manufacturing facilities in South Africa.

\section{Global generic medicine demand}

The majority of the people interviewed stated that in the last 20 years there has been an increase in the production of generic drugs predominantly in developing countries in Asia and most notably in India and China. This general shift of total global drug production volumes from the west to the east has been driven by the rising demand for generic medicines in developing countries. These developing countries previously had poor access to affordable medicines. Often the governments of developing countries have provided their local pharmaceutical industry with protection from competing with imported drugs by establishing high import tariffs for imported medicines. These governments also often provide incentives, e.g. tax incentives when the manufacturers are able to export medicines.

This trend has enabled the pharmaceutical manufacturing capability and capacity in a country like India to advance and grow. A representative from the DTI mentioned that up until fairly recently India used to be the seventh-largest producer of medicines globally. With the tremendous growth experienced in the Indian pharmaceutical industry, India has, in the last four years, become the world's secondlargest producer of medicines and has a pharmaceutical production volume output equivalent to Germany's. The capability of the Indian pharmaceutical industry has resulted in its ability to attract contract-manufacturing opportunities from large MNCs that have outsourced their production activities in order to focus on R\&D. An interviewee from a large local generic medicine manufacturer claimed that India has the largest number of FDA-approved production facilities outside of the U.S. and has, according to another 
local manufacturer and importer, become the "pharmacy to the world".

With an increase in the usage of generic medicines globally the demand for generic medicines has also increased in South Africa. Post 1994 and especially after the establishment of the South African government's NDP in 1996 an emphasis has been placed on increasing the general population's access to medicines. An opportunity has therefore been created for both large and small local manufacturers of generic medicines and in particular those that have already been manufacturing generic medicines. Importers of finished generic products, APIs and raw materials into South Africa have also benefited from this increase in demand. A respondent from an MNC based locally stated that this has created an opportunity for local importers to import finished generic products, APIs and raw materials predominantly from India, as local pharmaceutical manufacturers do not possess the economies of scale to meet the total demand for generic medicines locally. The importation of cheaper generic medicines has increased the competition within the local industry, which has placed a greater emphasis on low cost and high volume production locally.

\section{Price controls and TRIPS}

It is evident from the literature review that price controls on medicines have had an impact on the production of medicines globally (see Danzon, Mulcahy \& Towse, 2011). The effect of these price controls, however, is unique to the government in each country that establishes a system of price controls. Most price controls implemented globally have been to reduce medicine prices and this has also resulted in the increased demand and usage of generic medicines in both developed and developing countries.

IPR issues have had an effect on both global and local pharmaceutical manufacturing. The Medicines and Related Substances Act 90 of 1997 has made provision for both parallel importation and compulsory licensing. Respondents noted that the legal provision for parallel importation and compulsory licensing poses a minor risk for MNCs wishing to invest in South Africa. The risk exists that the IPRs of MNCs on a patented medicine could be threatened in the event of a national health crisis like HIV/AIDS that requires large-scale treatment with that medicine. Despite the perceived risks, all the respondents agreed that intellectual property issues had little effect on the decisions made by MNCs to withdraw their manufacturing presence from South Africa.

\section{Local factors impacting on the changing structure of South African pharmaceutical production}

Respondents noted that for the most part, the environment of the local pharmaceutical production industry appears to be influenced by two opposing objectives. The first objective is the South African government's objective of ensuring a continuous and sustainable supply of affordable quality medicines to meet the healthcare needs of the entire population. The industry's objective, on the other hand, is to remain sustainable and profitable in order to reward its shareholders. In doing so, the industry has to find ways to operate successfully within the confines of the government's legislation and policies by responding collectively in order to influence new legislation and policies. Both the government and the industry therefore need to be able to work together harmoniously in order to achieve these interdependent objectives.

All the respondents stated both directly and indirectly that the largest factor to influence the local manufacturing industry was the government's responsibility in increasing the entire South African population's access to affordable quality medicines. This responsibility has further been given a higher priority with the growing prevalence of diseases such as HIV/AIDS and TB. The DOH has increased access to affordable medicines by introducing price controls in the form of the SEP and by providing for parallel importation and compulsory licensing.

\section{Strategic vision of large local manufacturers}

From the pharmaceutical manufacturers' point of view the greatest change that has occurred is the response of the largest local generic medicine producers to the decline in manufacturing presence locally. With a growing market for affordable medicines globally and, the South African government's increased drive to improve access to medicines, opportunities still exist for local pharmaceutical manufacturers, particularly for the three or four largest companies manufacturing generic medicines. One respondent from an $\mathrm{MNC}$ with a local manufacturing presence emphatically stated that the market for generic medicines in South Africa would: "grow and grow and grow and grow and grow". All of the manufacturers that were interviewed agreed that this response to external global factors and internal legislative parameters and objectives has resulted in the largest change in recent pharmaceutical production. South Africa's largest generic drug producer appears to have been the most innovative in capturing local opportunities, firstly, and then international opportunities, thereby taking the lead within the local pharmaceutical manufacturing industry.

With the government's legal provision for compulsory licensing, the largest generic producer was the first to negotiate an alternative solution to overcome the government's intention to issue compulsory licences to provide ARVs in the treatment of HIV/AIDS. A senior executive from this company who was interviewed commented that in the late 1990 s the company realised that it needed to achieve economies of scale in order to fund the investments required in its production facilities to upgrade them from local MCC standards to gain international accreditation from organisations such as the WHO and the FDA. This was undertaken in order to exploit future export markets as part of an expansion strategy. At the same time there was an increase in global funding available for the manufacturing of ARVs and this included funding from the Clinton Foundation and PEPFAR shortly thereafter. Together with the available funding there was a large market with a large demand for ARVs but no local manufacturer with the capacity to meet this demand. This company had also approached large global MNCs like GlaxoSmithKline 
(GSK), Bristol-Myers Squibb (BMS), Eli Lilly and Gilead Sciences to gain voluntary licences to manufacture ARVs. These voluntary licences included technology transfers from the MNCs and enabled the large local manufacturer to increase its economies of scale. The manufacturer also became the first manufacturer globally to gain FDA approval to manufacture generic ARVs. These successes have enabled the company to reinvest in its manufacturing capabilities, which has resulted in gaining FDA approval for a sterile manufacturing plant, which has enabled the company to export large volumes of eye drops to the U.S. The respondent commented that the company's success had been achieved through vision and fortitude. This vision has led to this company to attain 11 manufacturing plants locally, export products to 100 markets globally and attain a physical presence in the U.K., U.S., Latin America, East and West Africa, Australia, the Middle East, Asia, and shortly in South East Asia (at the time of the interview in 2009). The second-biggest global MNC, GSK, now has a $19 \%$ stake in the business and the company is licensing products to GSK and manufacturing branded products for Eli Lilly and Gilead Sciences. At the time of the interview the company was between the twelfth- and fourteenth-largest generic medicines manufacturer globally.

\section{Capacity constraints of the MCC}

Five of the respondents indicated that the inefficiency of the MCC has resulted in delays in the registration process of new patented and generic medicines and delays in other administrative functions performed by the MCC. With such delays companies could potentially lose market share to other suppliers of therapeutically similar medicines in the market. The respondent from the MCC explained that the MCC has experienced capacity constraints because it is understaffed. In 1998 it employed 100 staff members and received about 300 applications for the registration of new medicines. Currently it employs 107 staff members and receives about 1,700 applications per annum. This, according to the respondent, is the main reason for the administrative backlog of the MCC and for the local registration of medicines being four times longer than the global average. The MCC, according the respondent, is moving towards becoming a statutory body as an independent organisation, which would enable it to negotiate its own salary levels and staff requirements. Previously the MCC was forced to work within the boundaries of the $\mathrm{DOH}$, where posts for specific technical requirements were restricted to a limited number of people.

A respondent from a local manufacturer and importer of generic medicines commented that the inefficiency of the MCC has inadvertently protected the local industry. Had the MCC had been more efficient, in this respondent's opinion, a greater number of competing Indian importers would have registered many more products locally, resulting in greater competition on the basis of price. If the MCC's efficiency were therefore to be improved, the government would have to find other means to protect local players from competing with cheaper imported products. The greatest impact on local production from the point of view of the MCC came about with the amendment to the Medicines and Related Substances Control Amendment Act 90 of 1997 which was promulgated in 2003. In particular section 22C of the Act, which has granted the MCC the authorisation to issue manufacturing licences to local manufacturing companies that comply with the PIC/S and the 2009 GMP standards. The regulatory authority also now has the authority to withdraw a licence should a local manufacturing company not comply with these current standards. Prior to this the MCC had no real authority to close down non-compliant facilities. Two of the respondents indicated that the manner in which the MCC has enforced compliance with the PIC/S and the 2009 GMP standards has been problematic. A respondent from a global generics producer that relies on the production capacity of smaller local contract manufacturers said that the requirements to attain a manufacturing licence are often below the requirements of the company's global production standards. This makes sourcing local companies to conduct contract manufacturing problematic, as their standards are often too low. This respondent suggested that a greater collaborative approach between manufacturers and the MCC must be adopted in order to ensure that manufacturers become compliant with current local manufacturing standards. In doing so, this respondent felt that manufacturers that comply with standards must be provided with incentives or stand a greater chance to provide medicines for government tenders.

\section{Single exit pricing (SEP)}

The government introduced the SEP system in 2004 in order to increase the access to affordable medicines and reduce healthcare costs in general. The respondent from the DTI made the observation that South Africa used to be the only country outside the U.S. that did not have some form of price control over medicines. Another respondent from an industry organisation commented that because of this South Africa used to be an attractive market for MNCs. All the respondents commented that price controls have had the effect of reducing the profit margins on medicines that are sold locally. This has resulted in increased pressure on suppliers to increase their economies of scale in order to reduce the cost per unit produced. One small local manufacturer commented that the reduction in prices could also result in local supply issues, where some companies stop the production of certain products, as it no longer remains economically viable to produce them locally. Two respondents from local manufacturers of generic medicines mentioned that the price controls also force local companies to source certain finished products from other markets like India. In some cases one of these local companies has also moved some of its manufacturing facilities to India in order to reduce costs to compete locally on price.

Two of the smaller suppliers of medicines who rely on contract manufacturing claimed that the SEP determined for the year is not predictable and this makes forecasting and budgeting activities difficult. It is therefore difficult to forecast what the costs of the companies' other activities, like marketing, should be in order to still be able to realise a profit. Respondents from two MNCs and an industry organisation expressed the fear that the benchmark pricing regulations that are currently being considered by the government could further reduce the viability of producing medicines locally. Benchmark pricing could mean that the 
local price of medicines would be determined by lowest price at which these products are sold in a grouping of four other countries. The outcome and implementation of this proposal is, however, not certain at this stage and pricing is currently only determined by the SEP system. A respondent from an industry organisation commented that this uncertainty over the implementation of benchmark pricing further contributes to a general uncertain investment environment.

The government's intention of establishing a unified, equitable and integrated national health insurance system in the form of the proposed National Health Insurance (NHI) scheme would in theory create a very large market for medicines in South Africa. Five of the respondents raised concerns about the NHI and what implications it might have, but as the implementation of such a system is not clear at this stage they could only speculate. Two respondents from MNCs and two from industry organisations predicted that under such a system the demand for generic medicines within South Africa could increase drastically. Concerns were raised about the influence and downward pressures this would have on medicine prices. The respondents speculated that under these conditions the market would initially be very competitive until the prices dropped to such an extent that the local manufacturers would withdraw their products from the market. The government would then have to import cheaper medicines to meet the local demand and this might impact on security of supply and quality issues.

\section{Industrial policies}

A respondent from one of the largest local manufacturers commented: "The intense regulatory period that the industry has faced in the last ten to 15 years has been unabated and every time you think you pass a regulatory hurdle for example benchmark pricing or NHI, another arises. The industry has been characterised by regulatory uncertainty and unpredictability." The respondents' reactions to the government's policies were for the most part not particularly favourable. They pointed out that although the DTI has targeted this sector as a priority, there are conflicting signals being given from other departments particularly from the $\mathrm{DOH}$.

DTI's National Industrial Policy Framework (NIPF) and Industrial Policy Action Plan (IPAP) include the pharmaceutical industry among the "lead sectors" targeted for economic intervention. The action plan focuses on the designation of the production of ARV's as a "strategic industry", and on the expanding local capabilities / increase domestic production of ARV's through leveraging the ARV tender. Over R8 billion went out on state tender in terms of drug procurement during 2009 and 2010 alone. Also about R900 million in DTI incentives were given to pharmaceutical projects under various DTI programmes between 2003 and 2008. Furthermore, the pharmaceutical sector is amongst "priority sectors" in the new Enterprise Investment Programme - Manufacturing (EIP - MIP), which is a tax-free cash grant to upgrade small and medium pharmaceutical plants to cGMP standards. The overall objectives of the programme are to increase the competitiveness of manufacturing sectors by promoting / incentivising investment in advanced technologies (new products), equipment and skills.

Some local manufacturers have benefited from the incentives that have been provided to local manufacturers, but as one respondent from an industry organisation commented the provision of these incentives mostly favours large generic medicine producers with a manufacturing presence. This could result in a declining demand for innovative-patented medicines provided by MNCs. A respondent from a large generic medicine producer also commented that the Indian pharmaceutical industry enjoys many more incentives, such as tax breaks and defensive import tariffs against importing medicines into India. This generally puts local manufacturers at a disadvantage against importers, who are often able to compete for the public procurement programmes based on the fact that their medicines are set at a lower price.

\section{Imported inputs}

All of the respondents were in agreement that importing APIs, raw materials and in some cases processing equipment has had a negative impact on the cost of producing medicines locally. Risks are also evident when APIs are in short supply, causing a shortage of a locally produced medicine. One respondent also noted that large suppliers often focus on supplying larger markets like the U.S. and Europe first, which could further lead to a local shortage. A respondent from a government department claimed that 99 per cent of the APIs and raw materials used in locally produced formulations are imported. This has an additional negative impact on the local trade balance, especially when one views the high costs of the APIs used for ARVs. Three respondents estimated that APIs in general contribute about 60 to 80 per cent of the cost of medicines and that, therefore, if these APIs were produced locally this would improve the trade deficit. The DTI is meeting regularly with the top producers of ARV APIs to encourage them to produce these APIs in South Africa. The willingness of these producers to invest in an API production facility locally appears to depend on the type of incentives that the government is willing to provide them with for establishing an API plant in South Africa.

Respondents from an MNC and two industry organisations doubted the viability of such a venture because to justify the expense of establishing an API plant the volumes produced would have to be larger than the local demand in order to make such a facility economically viable. It therefore seems doubtful that any manufacturer would be willing to invest in such an endeavour. One industry organisation after analysing this proposition found that sourcing from a local API producer would not be viable if the price of that API on the global market was less than the local suppliers' price. Two respondents noted that it would be strategically important for South Africa to produce a limited range of APIs required for diseases that are prevalent regionally and in the rest of Africa. South Africa could then exploit the markets within Africa with locally produced APIs and medicines and even become a centre of excellence for products demanded in Africa. Starting such an industry could also lead to other opportunities in the chemical 
industry that would supply intermediate chemicals used in the production of APIs. These industries could further provide opportunities to build skills locally and provide opportunities for innovation within the local pharmaceutical sector.

\section{Local skills shortage}

All the respondents saw the local skills shortage within the pharmaceutical manufacturing industry as being problematic. The skills that appear to be in the shortest supply are the skills of pharmacists within the manufacturing industry. A third of the respondents emphasised that South African pharmacists at university level are primarily trained to become community pharmacists and as a result of this are fairly ill equipped to operate affectively in a pharmaceutical production environment.

The largest local manufacturer noted that its in-house skills had lagged behind its manufacturing ability and that this had been corrected by bringing in skilled people from Europe and India to act as trainers within local facilities to facilitate in addressing this lag. The second-largest local manufacturer commented that it had been necessary to import skills to facilitate local in-house skills transfer. Another respondent noted that the industry should find ways of providing pharmacist interns with opportunities to gain industrial experience and also find ways of increasing the skills of other technical people within the facilities to reduce the dependence of pharmacists at all the levels of pharmaceutical production.

Numerous other issues were raised by respondents, such as

- $\quad$ impacts that BEE has on the employment of persons who lack sufficient skills and require an opportunity to gain skills, which impacts on costs;

- $\quad$ high costs of employing professional skills compared to India;

- the demise of the Pharmaceutical Production Technology course that offered pharmaceutical technicians training within a production environment (this course was previously administered by the Pharmaceutical Manufacturers Association (PMA));

- the reduced number of people entering the pharmacy profession;

- the important contribution that the pharmaceutical industry makes to skills within South Africa; and

- the generally high cost of skilled and semi-skilled labour within the industry.
Implications of the changing structure of the local pharmaceutical industry and the industry response

On a broad level the local pharmaceutical production industry's structure has changed from being dominated mostly by MNCs and a few local players to becoming an industry with a few large local generic medicine companies. With the gradual closure of manufacturing facilities by large MNCs and the government's emphasis on increasing access to cheaper generic medicines, the biggest change has come about by the largest generic medicine producers attempting to find value within the local market. The constraints of government legislations and policies and the general regulation environment have provided the largest local manufacturers with hurdles that have been overcome through innovation and a determination to remain viable. The potentials of a large local market and the prospects of unexploited export markets have created further opportunities for growth and sustainability for local manufacturers and local contract manufacturing. The growth of the local industry has become of strategic importance to the government, as seen by the IPAP, with its emphasis on ensuring the security of the supply of medicines locally and on stimulating the economy in order to reduce the trade imbalance. It has become clear that an improvement in the cooperation and communication between the government and the industry is of strategic importance to both parties in achieving their objectives.

\section{Opportunities within the transformed industry}

As mentioned previously, with the closure of the MNCs' production facilities, the largest local companies experienced growth. This growth was facilitated by the manufacturing of ARVs through voluntary licensing agreements which enabled technology transfers, the achieving of economies of scale and the gaining of international accreditation, in particular FDA approval of the two largest manufacturers' facilities. This situation has also resulted in local manufacturers with the potential to exploit export markets in developed countries. One respondent noted that despite the higher cost of local production it is in some cases still lower than the cost in developed countries like the U.S. and countries in Europe. In addition to this, South Africa has good infrastructure and a sound regulatory environment, with an emphasis on quality compared to other countries where low-cost medicines are produced.

Part of the intention of the IPAP was to place an emphasis on preferential procurement from local manufacturers, especially with the provision of ARVs to the public sector. A respondent from a local generic medicine producer and importer commented that the price of one particular ARV supplied to the state tender is still nine times more expensive than the price at which Indian companies sell the drug to other African countries. In this respondent's opinion sourcing medicines locally is not necessarily going to increase the access to medicines in the long term. Furthermore it will not be viable to protect local pharmaceutical manufacturing and the employment within this industry at the cost of denying about 50 million people access to affordable medicines. 
The respondent from the largest local manufacturer stated that sourcing from importers may be cheaper but by denying the economic viability of local producers the government, in addition to negatively affecting the balance of payments through increased importation, could lose in terms of tax collection and the local producers' ability to improve employment and skills locally. The purpose of the IPAP in this respondent's opinion is to allow South African companies to compete on equal terms with other countries like India, which are primarily able to be low-cost suppliers owing to the protection they enjoy from their government. A local manufacturer, however, noted that providing incentives for local manufacturers might present opportunities that are attractive for Indian or Chinese companies to manufacture in South Africa. If the government made it a prerequisite for interested foreign manufacturers to manufacture in South Africa and to have an empowered company when supplying drugs to the public sector, this would provide fair competition to other players within the local industry.

Almost all the respondents mentioned that the local industry had not yet been able to exploit the growing market for medicines in Africa, and that South Africa has the infrastructure and a good regulatory environment for supplying quality medicines to Africa. Two respondents commented that South Africa should become a regional hub for pharmaceuticals where medicines required in Africa should be produced in Africa. In support of this, another local manufacturer suggested that, in order to assist the introduction of products into the rest of Africa there should be an attempt at establishing a regional regulatory authority.

\section{Co-operation within the industry and with government departments}

All the respondents that were interviewed commented on the increasing trend in which local companies enter into marketing, licensing or manufacturing agreements with larger MNCs. The motivation behind this trend appears to be supported by a new confidence that the large global pharmaceutical corporations have in local manufacturing capabilities. For the largest local manufacturer, this has resulted in being 19 per cent owned by GSK, which appears to be a mutually beneficial arrangement for both parties to extend product lines and exploit global markets. The second-largest manufacturer, according to a respondent, is now also entering into marketing agreements with another large MNC, which apart from recognising the manufacturer's production capabilities also realises the value of this manufacturer's exclusive distribution network within South Africa and regionally. All the other companies that were interviewed are either MNCs that have contracted work out to local companies or are local manufacturers that conduct contract manufacturing for MNCs. In addition to this, there are also MNCs that still have manufacturing presence and have spare capacity to manufacture products for other MNCs that no longer have facilities to manufacture locally marketed products.

This represents another important change within the local pharmaceutical industry, as very few companies now operate in complete isolation from other companies. This trend could result in greater co-operation within the manufacturing industry and the creation of new smaller manufacturing companies and perhaps a regional manufacturing hub. Respondents from industry organisations also highlighted possible further trends that may occur within the manufacturing industry. One of these trends is the possible backward integration of large medicine retailers into pharmaceutical production in order to manufacture their own brands and to save on the costs of sourcing from contract manufacturers. Another possibility is that the government may itself establish state-owned pharmaceutical manufacturing facilities in order to achieve economies of scale with a large market. The establishment of Public Private Partnerships (PPPs) between local companies and the government has also been mentioned as a possible solution for reducing prices and increasing access to medicines predominantly in the public sector.

Almost all the respondents agreed that the industry, through its various industry organisations, is able to respond to and communicate collectively with government departments. In many cases the nature of the interactions between the industry and government seems to be influenced by distrust from both parties, which fail to create a constructive forum to address important issues and to understand the other party's concerns, objectives and points of view. The majority of the respondents also commented on the lack of cohesion between the various government departments. A respondent from a government department specifically mentioned that there is as yet no clear industrial policy for the pharmaceutical industry and that when the DTI had started to establish a policy in 1999 the DOH and the Treasury were not forthcoming or willing to adopt a strategy as these stakeholders had their own interests. This respondent claimed that: "The DTI tries to balance the points of view of the DOH, Treasury and the pharmaceutical industry. All these stakeholders have different interests and it is essential that they agree on the same strategy."

\section{The future of pharmaceutical production in South Africa}

Of the 12 respondents, all apart from two believed that the future holds many opportunities for local pharmaceutical production and in particular the production of generic medicines. By contrast, one respondent from a government department indicated that if there is no intervention from government in the form of a strategic plan or comprehensive industrial policy there will be a complete decline in local pharmaceutical production by the year 2020. Another respondent from a large local producer and importer of generic medicines commented that increasing access to medicines by importing less expensive generic medicines is of greater importance than creating capacity in local manufacturing facilities.

The remaining ten respondents raised several issues that could determine the future success of local pharmaceutical manufacturing. In general, the quality of produced medicines appears to be recognised as one of the main characteristics that will determine the acceptance of locally produced medicines in the local market and in export markets. A high quality can only be achieved by re- 
capitalising existing facilities in order to meet the local and where applicable international regulatory requirements. The MCC in particular has noted that the upgrade in local facilities is indicative of growth and expansion.

The emphasis on the provision of cheaper generic medicines and essential drugs locally appears to be the main threat to the market share of patented innovative medicines. Issues regarding the protection of intellectual property and price controls pose further threats not just to manufacturing presence but to the marketing of patented medicines in general, especially in the environment of the proposed NHI. The MNCs are, however, in consultation with the government to emphasise the important role that innovative or patented medicines can play locally. These medicines are often therapeutically superior to older generic medicines and have a high benefit to cost ratio which could reduce other healthcare needs such as hospitalisation. Within the context of the NHI there may also be certain medicines that are required for obscure diseases that are only supplied by companies providing innovative-patented medicines. In addition to this, the patented medicines on the local market are able to become the generic medicines of the future once the patent has expired. Despite this, MNCs are beginning to partner with local companies to manufacture products that are unique to the local market and are not produced elsewhere. At another level MNCs are approaching local companies to manufacture for global markets.

In general, the next step in the industry's growth appears to be to capture profitable export markets in Africa and beyond. So far, only South Africa's largest manufacturer has had the vision and the capacity to execute a global expansion strategy successfully. For the remaining manufacturers success will most likely depend on how they embrace market opportunities with their current product portfolios and how they devise strategies to exploit other markets with large growth potentials. A comprehensive industrial strategy will have to be implemented after consultation with the entire local manufacturing industry in order for both industrial and government objectives to be achieved.

\section{Conclusion}

The changing structure of pharmaceutical manufacturing in South Africa can be characterised as an industry that previously had many manufacturing facilities operated by MNCs and a few local players. The global and local factors impacting on the industry had resulted in the largest local manufacturers playing more dominant roles within the local industry and the MNC manufacturers gradually decreasing their manufacturing presence locally. At the same time a few smaller local manufacturers have been able to remain viable by producing lower volumes of products destined for smaller niche local markets and in some cases export markets.

On a broader policy level the DTI has realised the importance of this sector and it has been designated a priority sector in the IPAP in order to ensure that the industry remains viable and sustainable. Unfortunately, the DTI's attempt at providing a pharmaceutical strategy is not met with tremendous support and strategic cohesion from the other government departments like the $\mathrm{DOH}$ and the Treasury. The pharmaceutical industry, in general, also appears reluctant to become involved in aiding the government in establishing a general strategy for the pharmaceutical sector. If a successful strategy is established for the pharmaceutical industry after joint consultation of all the stakeholders, it could mean that some manufacturers would invest locally or possibly re-invest locally provided that such an industrial strategy is able to offer sufficient incentives that make such investments attractive, address the skills shortages and reduce regulatory uncertainties.

The international experience with new emerging multinational pharmaceutical companies demonstrates the importance of industry developing dynamic capabilities in response to exogenous shocks brought about by trade liberalisation. In South Africa these shocks have negatively affected production and resulted in reduced investment in new capabilities. The Indian case (Athreye et al., 2009; Chittoor et al., 2009) shows that dynamic capabilities can co-evolve with firm strategy in order to exploit new opportunities brought about by regulatory changes. The question for South Africa is whether the DTI's recent industrial policies will act as a catalyst to the pharmaceutical industry not only to increase investment and production but to develop new capabilities that will provide a long lasting competitive advantage?

\section{References}

Athreye, S., Kale, D. \& Ramani, S. 2009. 'Experimentation with strategy and the evolution of dynamic capability in the Indian pharmaceutical sector', Industrial and Corporate Change, 18(4): 729-759.

Beare, M. 2001. Pharmaceutical Sector Investment Scoping Initiative - A strategic study to identify investment opportunities. Johannesburg: Development Bank of Southern Africa.

Chittoor, R., Sarkar, M., Ray, S. \& Aulakh, P. 2009. 'Thirdworld copycats to emerging multinationals: Institutional change and organisation transformation in the Indian pharmaceutical industry,' Organization Science, 20(1): 187205.

CMS. 2007. Council for Medical Schemes Annual Report 2006-7. Pretoria: Council for Medical Schemes.

Cockburn, I. M. 2004. 'The changing structure of the pharmaceutical industry', Health Affairs, 23(1):10.

Danzon, P., Mulcahy, A. \& Towse, A. 2011. Pharmaceutical pricing in emerging markets: Effects of income, competition and procurement. NBER Working Paper 17174. Boston: NBER.

DOH. 1996. National drug policy for South Africa. [0nline] URL: http/www.doh.gov.za/docs/policy/drugsjan1996.pdf. Accessed 30 March 2008.

FRIDGE. 1999. Pharmaceutical manufacturing sector 
study. Industry sector report, LABAT Africa/ Chemical Marketing Consultant Services (CMCS), South Africa.

Heracleous, L. \& Murray, J. 2001. 'The urge to merge in the pharmaceutical industry', European Management Journal, 19(4):430-437.

Maloney, C. \& Segal, N. 2007. The growth potential of the pharmaceuticals sector in South Africa. Industry sector analysis report, Genesis Analytics (Pty) Ltd, Johannesburg.

McIntyre, D. \& Thiede, M. 2007. 'Health care financing and expenditure'. In Harrison, S., Bahna, R. \& Ntuli, A. (eds.). South African Health Review 2007. Durban: Health Systems Trust, pp. 35-46.

Scherer, F. M. 1993. 'Pricing, profits and technological progress in the pharmaceutical industry', Journal of Economic Perspectives, 7(3): 97-115.

Taylor, B. 2007. 'Rationing of medicines and health care technology'. In Harrison, S., Bahna, R. \& Ntuli, A. (eds.). South African Health Review 2007. Durban: Health Systems Trust, pp. 123-137.

Yeoh, P. \& Roth, K. 1999. 'An empirical analysis of sustained advantage in the U.S. pharmaceutical industry: Impact of firm resources and capabilities', Strategic Management Journal, 20(7):637-653. 


\section{List of abbreviations}

\begin{tabular}{|c|c|}
\hline Abbreviation & Definition \\
\hline API & Active pharmaceutical ingredient \\
\hline ARV & Antiretroviral \\
\hline BEE & Black Economic Empowerment \\
\hline cGMP & Current Good Manufacturing Process/Practice \\
\hline $\mathrm{DOH}$ & Department of Health \\
\hline DTI & Department of Trade and Industry \\
\hline DST & Department of Science and Technology \\
\hline FDA & Food and Drug Administration \\
\hline GMP & Good Manufacturing Process/Practice \\
\hline IPRs & Intellectual Property Rights \\
\hline IPAP & Industrial Policy Action Plan \\
\hline M\&A & Mergers and Acquisitions \\
\hline PIASA & Pharmaceutical Industry Association of South Africa \\
\hline $\mathrm{PIC} / \mathrm{S}$ & $\begin{array}{l}\text { The Pharmaceutical Inspection Convention and Pharmaceutical Inspection Co-operation Scheme } \\
\text { (jointly referred to as "PIC/S") }\end{array}$ \\
\hline $\mathrm{R} \& \mathrm{D}$ & Research and Development \\
\hline SEP & Single Exit Price \\
\hline TRIPS & Trade-Related Aspects of Intellectual Property Rights \\
\hline WHO & World Health Organization \\
\hline WTO & World Trade Organization \\
\hline
\end{tabular}




\section{APPENDIX A: Research instrument}

1. What recent trends and changes in the global pharmaceutical industry have had an impact on local pharmaceutical production in general?

2. How have the characteristics or behaviours of global multinational pharmaceutical companies affected the local pharmaceutical industry?

3. How has global drug demand influenced the demand for locally manufactured pharmaceuticals and how has this influenced competition within the industry?

4. How have global price controls affected the pharmaceutical production in South Africa?

5. How have global patent protection and Intellectual Property Rights (IPRs) issues (e.g. parallel importing and compulsory licensing) influenced local pharmaceutical manufacturing?

6. Which factors within South Africa have had the greatest impact on local pharmaceutical production?

7. How have the characteristics or behaviours of local pharmaceutical companies affected the local pharmaceutical industry?

8. How does the unavailability of locally manufactured inputs (e.g. active pharmaceutical ingredients and processing equipment) impact on local manufacturing?

9. What government regulations, legislations or industrial policies have had an impact on manufacturing medicines in South Africa (e.g. DOH's drug policy, MCC manufacturing licensing requirements, medicines registration, pricing policies or Industrial Policy Action Plans)?

10. Is there a skills shortage within the industry and if so how does this affect the local manufacturing industry?

11. What are the main implications of the changing structure in local pharmaceutical manufacturing and how has the local pharmaceutical manufacturing industry responded?

12. What are the implications of the government's regulations, legislations or industrial policies mentioned in section 2 and how has the pharmaceutical industry responded?

13. How are local manufacturers adapting to changes within the local pharmaceutical industry?

14. How have the volumes of locally produced drugs changed for this company or in general and what are the reasons for these changes?

15. What is the future of pharmaceutical production in South Africa?

\section{APPENDIX B: List of interviewees}

\begin{tabular}{l|l|l}
\hline No. & Position & Organisation \\
\hline 1. & CEO & Merck Serono \\
\hline 2. & Senior Executive & Aspen Pharmacare \\
\hline 3. & CEO & IMSA \\
\hline 4. & CEO & SAAPI \\
\hline 5. & Director: Technical Infrastructure Unit & DTI \\
\hline 6. & CEO & Mylan \\
\hline 7. & Director: & MCC \\
\hline 8. & Inspectorate and Law Enforcement & \\
\hline 9. & CEO & Specpharm Holdings \\
\hline 10. & COO & PIASA \\
\hline 11. & Senior Executive & Cipla Medpro \\
\hline 12. & Supply Chain Executive & Adcock Ingram \\
\hline 13. & CEO & Columbia Pharmaceuticals \\
\hline
\end{tabular}

